\title{
On Risk Bearing of the Sales Contract
}

\author{
Hanlin Dong \\ University of the Chinese Academy of Social Sciences, Beijing, China
}

\begin{abstract}
In the process of performance of the sales contract, the subject matter is not caused by the cause of both parties and the loss, and that damage should be borne by which party in the contract is involved in the sales contract risk burden. It is related to the fundamental interests of both buyers and sellers. Therefore, this issue has become a matter of great concern to both buyers and sellers. It is also one of the most important legal issues in the sales contract and plays a very important role in the contract law. This paper is aiming at the issues of the burden of risk in business contract and the improvement of the system of risk of business contract legislation suggestions, in order to make contract risk burden has a certain role in promoting.
\end{abstract}

Keywords: sales contract, risk bearing, ownership theory, delivery theory

\section{The Basic Issues of Risk Bearing of the Sales Contract}

\section{The Reasons for the Risk in the Sales Contract}

There must be risks in the signing and performance of contracts, and sales contracts are no exception. In addition to the obligor's subjective intention which consequently leads to compensation or punishment, there are also some cases where the law clearly stipulates that the obligor can be exempted from liability. The reasons for the obligor's exemption include:

Force majeure. According to Article 153 of China's General Principles of Civil Law, "Force Majeure refers to an objective situation that cannot be foreseen, avoided or overcome". Among them, "Unforeseeablity" is based on people's cognitive ability and belongs to subjective standards, while "unavoidability and insurmountability" is based on the parties' objective technical level, prevention condition and prevention ability and pertains to objective standards. When it comes to foresight, on the one hand, it depends on people's foresight ability, which should be based on the current technological level to judge whether people can foresee a certain phenomenon. On the other hand, it must be judged on the basis of ordinary people's ability to foresee instead of the parties' ability to foresee (Ding, 1998).

Accident. An accident refers to an incident that occurs by chance without the intention or negligence of the parties. As a statutory defense, accidents have been widely recognized in China's civil law academic circles and judicial practice. The legal bases are the provisions on civil liability in the civil law, such as Articles 106 and 126 of the General Principles of Civil Law in which the term "no fault" is generally considered to be a situation involving an accident.

The faults of a third party that the parties cannot foresee. The fault of a third person includes intentional and negligent acts. If the subject matter is damaged or lost, the damage compensation relationship

Corresponding author: Hanlin Dong, Master of Civil and Commercial Law, University of the Chinese Academy of Social Sciences, Beijing, China; research field: civil and commercial law. 
will occur between the party to the contract who suffers damage and the third party, but there still exists risk bearing between both parties to the contract, that is, only the party who bears the risk of the subject matter can claim compensation from the third party ( $\mathrm{Yu}, 2002)$.

\section{The Conditions for the Application of Risk Bearing System to the Sales Contract}

The problem of risk bearing can only occur in a contract with a specific object or after the species has been specified by the contract. Specific things or specific types of things are of unique and irreplaceable quality. Once they are accidentally damaged or lost during the performance of the contract, the delivery will be partially or even completely frustrated, and the contract will not be fulfilled, thereby resulting in the risk bearing problem.

\section{The Risk Bearing Theory and Legislative Case Analysis}

At present, there are mainly three kinds of theories about the time of risk transfer in academic circles. These three theories have different manifestations in the legislation of goods risk transfer in different countries and different periods in the world, and corresponding legislation cases have been formed accordingly.

\section{The Doctrine of Contract Establishment}

The doctrine of contract establishment is that the risk transfer of the subject matter in the sales contract is marked by the establishment of the contract, that is, as long as both parties reach an agreement on the contract, the risk liability of the subject matter will be borne by the buyer, regardless of whether the buyer possesses the subject matter or enjoys the ownership of the subject matter (Chen, 2004).

The legislative case of contract establishment doctrine. The laws stipulating the transfer of the risk liability of the subject matter in the form of statutory law include Roman law and Swiss liability law. Article 23 of Volume 3 of General Jurisprudence stipulates:

Once the contract of sale and purchase is concluded even without the written form, namely, once the parties have reached an agreement on the price, even if the sale and purchase of the subject matter has not been delivered, the buyer immediately bears all risks of its possession. Therefore, if the betrayed slave dies or any part of the body is injured and all or part of the sold building is burned... the loss should be borne by the buyer and the price should be paid even if he is not receiving the object ... The above provision is also applicable to other animals or other things. (Ding, 1998)

The analysis of contract establishment doctrine. The conclusion of a contract means consistency between the interests and the will of both parties. In practice, this risk bearing theory originated from contract establishment doctrine has its limitations. After the establishment of the contract, the subject matter is always under the possession of the seller before the seller actually delivers the goods. It is difficult for the buyer to prove whether the damage or loss of the subject matter is entirely due to the cause that cannot be attributed to both parties. As a consequence, it has irrationality to require the buyer to bear all the losses at risks (Wang, 2002).

\section{Ownership Theory}

With the rapid economic development, the risk transfer mode of the past contract establishment doctrine could no longer adapt to the development of the times, and the ownership theory facilitated a takeover.

Legislative cases of ownership theory. Since the 19th century, most countries have adopted the rule of risk transfer with the transfer of ownership. The characteristic of ownership theory is that it embodies the so-called legal proverb in Roman law that "natural disaster should be borne by all". Article 20 of UK's Law on Sale and Purchase of Goods stipulates that: 
The presumption of risk is transferred with the transfer of ownership. Unless otherwise agreed, the risk of the goods is still borne by the seller before the transfer of ownership of the subject matter. The risk is borne by the buyer after the transfer of ownership to the buyer, regardless of whether the subject matter is delivered or not. (Wang, 2002)

Analysis of ownership theory. The time of risk transfer can be determined based on ownership theory before the time of ownership transfer must be specified. National laws generally respect the autonomy of the parties for the transfer of ownership. In the absence of an agreement, the legal provisions governing risk transfer vary from country to country (Ji, 2015).

\section{Delivery Theory}

With the exposure of the drawbacks of ownership theory, the delivery theory that replaced it emerged and was widely applied.

Legislative cases of delivery theory. The theory that risk transfers with the delivery of the subject matter has been recognized by scholars and practitioners, as is stipulated in Austria, Germany, the United States, and the United Nations Convention on Contracts for the International Sale of Goods. For instance, Paragraph 1 in Article 446 of the German Civil Code stipulates: "From the time of delivery of the subject matter of the sale, the risk of accidental loss or accidental damage shall be transferred to the buyer" (Liu, 2015).

Comments on delivery theory. The application of delivery risk transfer requires a clear criterion for judging the allocation of risk bearing. The key to determine this standard is to clarify the transfer time of ownership, which needs to be judged by various standards. Moreover, the content of property ownership is separable, which is often seen in civil activities that the possession and ownership of property are separated, and property may temporarily be out of the control of the owner. At this time, the owner should fulfill the obligation to protect the property. Re-delivery doctrine, as the standard of risk bearing in sales contracts, also has its drawbacks. Goods whose ownership has not been transferred after delivery of the subject matter are not conducive to urging the seller to transfer ownership.

\section{Legislative Improvement of Risk Bearing of Sales Contract in China}

Although China's Contract Law draws on the legislative experience of the United Nations Convention on Contracts for the International Sale of Goods and adopts the principle of delivery, there are still some deficiencies in practice (Wang, 2013).

\section{The Risk Bearing of Goods in Transit}

The sale of goods in transit means that the goods are already in transit when the sales contract is established. When the contract is not established, the buyer of the goods is uncertain. For the sale and purchase of goods in transit, the goods have been loaded on the means of transport at the time of concluding the sales contract. Both the seller and the buyer may not know clearly whether the goods have been damaged or lost etc. Even if the goods arrive at the destination and are found damaged or lost, it is difficult to determine on which stage of the transport process the loss occurs. For the risk transfer of goods in transit, it is usually necessary to set up a contract as the limit of risk. Article 144 of China's Contract Law has specific provisions on this (Wu, 1996).

China's Contract Law absorbs the spirit of the United Nations Convention on Contracts for the International Sale of Goods, but unfortunately, it only quotes part of the Convention. In practice, if the damage to the goods is due to an accident, the time of the damage is often determined. However, when it comes to 
international logistics with relative bulk trading, the goods have a long journey time. Most of the buyers and sellers use documents to buy and sell, and can only judge the condition of the goods by the records on the documents. Once the goods are found to be damaged or lost after the arrival at the destination, it is very difficult to judge whether the damage or loss of the goods occurs before or after the establishment of the contract (Wessel, 2014).

\section{The Risk Bearing of Sale and Purchase of Non-specific Goods}

Although the subject matter of a sales contract may be non-specific, ownership is always a right to a particular object. Therefore, before distinguishing certain things from others of the same kind, the ownership of the kind of things in the contract cannot be transferred from the assignor to the assignee in any case. When it comes to the sale of non-specific goods, the Contract Law simply summarizes the term "subject matter" instead of distinguishing between specific goods and non-specific ones. Absorbing foreign legislative experience, the Contract Law is supposed to make a detailed division of the trade of this kind of non-specific goods to better classify risk and liability (Wang, 2015).

\section{The Risk Bearing of Real Estate Sale and Purchase}

In the vast majority of real estate transactions involving housing sales, delivery often precedes change registration, that is, when delivery occurs, ownership has not been transferred. From the buyer's point of view, no ownership is granted, and the double risk of accidental damage and loss of the house has to be borne. At present, although China has formulated a relatively complete real estate registration system and established the real estate registration system with wider coverage, in practice, it is not uncommon for real estate transactions to complete delivery without registration of ownership changes. If delivery doctrine is adopted to deal with real estate risk transfer, it is not different from the recognition or even protection of real estate delivery without real right transfer formalities. It is a weakening of the registration system of real estate change. Therefore, rational ideas are indispensable to solve the problem of risk transfer.

\section{Conclusions}

With the further development of market economy, China's domestic trade is flourishing day by day, and trade with other countries is becoming more and more frequent. How to establish a clear and reasonable risk-bearing system and coordinate the differences between risk legislation and other countries has become one of the problems that we need to solve urgently, because it has the functions of encouraging consumption, balancing interests, protecting transaction security, and stabilizing market economy. It has important significance. Although the current contract law of the country mainly stipulates the risk burden of sales contract in detail on the basis of transplanting the provisions of some conventions, it is not perfect. This is the starting point for the author to study the system.

This paper expounds the basic problems of risk burden in sales contracts and makes a comparative analysis of the three theories of risk burden. At the same time, it puts forward some suggestions on the improvement of risk burden clauses in the Contract Law of China, with a view to playing a certain practical significance. Due to the limitation of the author's level, the argument is inevitably not deep and rigorous enough. The author urges all teachers to criticize and correct it.

\section{References}

Chen, W. (Trans.). (2004). German civil code. Beijing: Law Press. 
Ding, M. (1998). Roman law contractual liability. Beijing: China University of Political Science and Law Press.

Ji, W. (2015). The construction of legal order (enlarged edition). Beijing: The Commercial Press.

Liu, J. (2015). Rationality, freedom and practical criticism. Beijing: Beijing Normal University Press.

Wang, L. (2002). Study on new problems of contract law. Beijing: China Social Sciences Publishing House.

Wang, L. (2015). Rule of law: Good law and good governance. Beijing: Peking University Press.

Wang, Z. (2013). Debt law principle (2nd ed.). Beijing: Peking University Press.

Wessel, V. (2014). Natural value. (G. Chen, Trans.). Beijing: The Commercial Press.

$\mathrm{Wu}$, Z. (1996). United States uniform commercial code cargo risk transfer clause. Journal of Zhongnan University of Economics and Law, 106.

Yu, Y. (2002). A comparative study on the transfer of ownership of goods and the risk burden. Wuhan: Wuhan University Press. 